\title{
Pengaruh Self Efficacy Terhadap Prestasi Belajar pada Mata Pelajaran Ekonomi
}

\section{(Survey Kepada Siswa-Siswa Kelas XI IPS SMAN Se-Kota Bandung)}

\author{
Amanda Utari ${ }^{*}$ dan Syamsul Hadi Senen ${ }^{2}$ \\ ${ }^{12}$ Fakultas Pendidikan Ekonomi dan Bisnis, Universitas Pendidikan Indonesia \\ *E-mail: amandautari@student.upi.edu
}

\begin{abstract}
Abstrak: Tujuan dari penelitian adalah untuk mengetahui pengaruh self efficacy terhadap prestasi belajar pada mata pelajaran ekonomi survey kepada siswa-siswa kelas XI IPS SMAN Se-Kota Bandung. Manfaat Penelitian ini adalah memberikan informasi bahwa pentingnya self efficacy dimiliki siswa dalam proses pemebalajaran. Populasi dalam penelitian ini sebanya 3907 siswa, sedangkan sampel penelitian di ambil sebanyak 363 siswa. Intrumen yang digunakan untuk data self efficacy berupa angket sebanyak 10 butir dan untuk data prestasi belajar siswa pada mata pelajaran ekonomi berupa nilai Ujian Akhir Semster (UAS). Analisis pengaruh self efficacy terhadap prestasi belajar siswa pada mata pelajaran ekonomi dengan menggunakan uji path sub struktur (uji $t$ ), nilai t hitung dan $t$ tabel dengan derajat kepercayaan $95 \%$ satu arah diperoleh sebesar 1,649. Karena thitung $>t$ tabel yaitu 9,961 >1,649, maka Ho ditolak dan Ha diterima. Yang berarti self efficacy berpengaruh terhadap prestasi belajar siswa SMA Negeri di kota Bandung, hal ini juga dapat diketahui dengan melihat nilai probabilitasnya yaitu sebesar 0,000 lebih kecil dari 0,05. Besarnya pengaruh self efficacy terhadap prestasi belajar adalah $(0,403)^{2}=0,1624=16,24 \%$.
\end{abstract}

Kata Kunci: Self Efficacy, Prestasi Belajar

UTILITY: Jurnal IImiah Pendidikan dan Ekonomi

Website : http://journal.stkipnurulhuda.ac.id/index.php/utility

Permalink: https://journal.stkipnurulhuda.ac.id/index.php/utility/article/view/279

How to cite (APA): Utari, A., \& Senen, S. (2018, February 1). Pengaruh Self Efficacy Terhadap Prestasi Belajar pada Mata Pelajaran Ekonomi. UTILITY: Jurnal IImiah Pendidikan Dan Ekonomi, 2(1), 1-9.

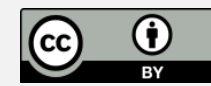

This is an open access article distributed under the terms of the Creative Commons Attribution 4.0 International License, which permits unrestricted use, distribution, and reproduction in any medium, provided the original work is properly cited.

\section{PENDAHULUAN}

Pendidikan merupakan salah satu aspek yang sangat penting dalam meraih sebuah prestasi. Mengingat posisi pendidikan yang sangat strategis dan sentral 
dalam membentuk dan membina sumber daya manusia Indonesia yang berkualitas dan berprestasi, maka masalah pendidikan menjadi pusat perhatian bagi bangsa Indonesia (Minauli, 2015). Prestasi belajar merupakan salah satu indikator terpenting dalam pembelajaran dan pemahaman di semua sistem pendidikan (Sedaghat, Abedin, \& Hejazi, 2011). Peningkatan prestasi akademik peserta didik menjadi pembahasan dari kalangan pendidik, orang tua, bisnis dan masyarakat (Korelich \& Maxwell, 2015).

Pengetahuan dan literasi ekonomi penting untuk bisa menjadi manusia yang berfungsi secara efektif di masyarakat sekarang ini dengan perekonomian dunia yang semakin terhubung (Mead \& Sandene, 2007:1). Pemahaman tentang ekonomi akan membantu para peserta didik yang akan melanjutkan ke perguruan tinggi atau memasuki dunia kerja menjadi warga negara yang bertanggung jawab secara finansial (NCES, 2013:1). Tujuan utama dari mata pelajaran ekonomi adalah untuk menyiapkan peserta didik dengan pengetahuan yang diperlukan untuk memahami dunia dan membuat pilihan yang lebih baik (Thompson, Butters, \& Asarta, 2011) serta menyiapkan mereka untuk berperan sebagai pelaku ekonomi dimasa depan (Butters, Asarta, \& Thompson, 2013).

Permasalahan rendahnya prestasi akademik peserta didik khususnya pada mata pelajaran ekonomi juga terjadi di negara berkembang seperti Indonesia. Hal ini terlihat dari rendahnya rata-rata nilai Ujian Nasional, karena penilaian mutu program pendidikan di Indonesia salah satunya diukur melalui pelaksanaan Ujian Nasional untuk peserta didik kelas XI yang berfungsi mengukur kompetensi peserta didik (Kemdikbud, 2016). Direktur Jendral Peningkatan Mutu Pendidikan dan Tenaga Kependidikan (Dirjen PMPTK) Depdiknas dalam Baedhowi mengutarakan bahwa untuk meningkatkan prestasi belajar siswa maka seorang guru dituntu mampu menerapkan cara belajar yang menarik (Uno, Hamzah B. dan Mohammad, 2011:162-163). Guru sebagai salah satu mediator dan komponen pengajar mempunyai peranan yang sangat penting dalam mencapai tujuan pembelajaran dan sangat menentukan kebehasilan proses pendidikan, karena guru terlibat langsung didalamnya. Ini sesuai dengan pernyataan Mason dalam jurnal penelitian yang berjudul Teacher as Critical Mediator of Knowladge yang menyatakan bahwa "teacher as actively mediating between what is know and what is not yet know by the learner" (Mason, 2000:348). 
Self efficacy juga memiliki peran penting dalam meningkatkan prestasi peserta didik, kenyataanya yang terjadi dalam dunia pendidikan hasil belajar tidaklah cukup karena banyak peserta didik yang masih kurang percaya diri tidak yakin dengan kemampuan yang dimiliki atau pasrah saja menerima nasib (Atya, 2017). Beberapa peserta didik memiliki permasalahan-permasalahan, baik permasalahn akademik (prestasi belajar) maupun permasalahn perilaku peserta didik yang meliputi kemampuan mengendalikan diri, motivasi diri sendiri, ketahan menghadapi frustasi, mengatur susana hati, kemampuan menunjukan suasana hati, kurang bisa mengendalikan emosinya seperti mengendalikan diri dalam pergaulan dengan temanya serta kurang berempati terhadap teman (Minauli, 2015).

Kurangnya rasa kepercayan diri dalam melaksanakan tugas (Mahyuddin et al., 2006). Kesulitan dalam mengerjakan tugas serta beberapa peserta didik mengalami motivasi rendah dan kesulitan dalam belajar (Afari, Ward, \& Khine, 2012). Banyak yang berasumsi apabila telah memiliki self efficacy maka akan meningkatkan pencapaian prestasi sehingga mereka beranggapan telah melakukan yang terbaik dalam pembelajaran tetapi dalam kenyataan tidak memiliki dampak sama sekali (Mahyuddin et al., 2006).

Prestasi belajar dipengaruhi oleh 3 faktor, yaitu faktor internal, faktor eksternal dan faktor pendekatan belajar. Faktor internal merupakan faktor atau penyebab yang berasal dari dalam diri setiap individu tersebut, seperti aspek pisiologis dan aspek psikologis. Faktor eksternal dibagi menjadi dua macam, yaitu faktor lingkungan sosial dan faktor lingkungan non sosial (Muhibbin, 2008). Berdasarkan uraian di atas, maka penulis melakukan penelitian dengan judul "Pengaruh Self Efficacy Terhadap Prestasi Belajar Pada Mata Pelajaran Ekonomi” (Survey Kepada Siswa-Siswa Kelas XI IPS SMAN Se-Kota Bandung).

\section{METODE}

Metode penelitian adalah "prosedur atau cara-cara yang dapat dilakukan untuk melaksanakan penelitian”. Tujuan penelitian ini mencari gambaran dan menguji kebenaran tentang pengaruh self efficacy (variabel $\mathrm{X}_{1}$ ) terhadap prestasi belajar (variabel Y), maka jenis penelitian ini menggunakan metode penelitian deskriptif dan penelitian pengujian (verifikatif). 
Metode deskriptif adalah metode yang digunakan untuk menggambarkan atau menganalisis suatu hasil penelitian tetapi tidak digunakan untuk membuat kesimpulan yang lebih luas (Sugiyono, 2010). Penelitian pengujian verifikatif adalah "penelitian yang diarahkan untuk menguji kebenaran sesuatu bidang yangtelah ada" (Muhidin, 2011). Berdasarkan jenis penelitianya, yaitu deskriptif dan verifikatif yang dilaksanakan melalu penggumpulan data di lapangan, maka metode penelitian yang digunakan adalah metode survey.

Metode survey adalah penelitian yang dilakukan terhadap sejumlah individu atau unit analisis, sehingga ditemukan fakta atau keterangan secara faktual mengenai gejala suatu kelompok atau perilaku individu, dan hasilnya digunakan sebagai bahan pembuatan rencana atau pengambilan keputusan. Metode ini menggunakan kuesioner sebagai alat pengumpulan datanya (Muhidin, 2011). Berdasarkan pengertian di atas maka dapat disimpulkan metode survey untuk memperoleh gambaran antara self efficacy (variabel $\mathrm{X}_{1}$ ), terhadap prestasi belajar (variabel Y).

\section{HASIL DAN PEMBAHASAN}

Berdasarkan hasil penelitian yang telah dilaksanakan, hasil analisis path sub struktur digunakan untuk mengetahui pengaruh variabel self efficacy terhadap prestasi belajar siswa kelas XI IPS di SMA Negeri Kota Bandung. Analisis path sub struktur digunakan untuk menjawab hipotesis penelitian:

Ho : Self Efficacy tidak berpengaruh terhadap prestasi belajar

Ha : Self Efficacy berpengaruh terhadap prestasi belajar

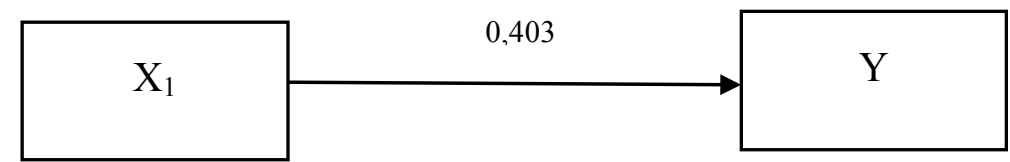

\section{Gambar 1}

Sub Struktur

Berikut ini hasil analisis data, maka diperoleh model koefisien regresi dan koefisien jalur variabel $\mathrm{X}_{1}$ terhadap $\mathrm{Y}$. 
Tabel 1

Hasil Analisis Sub-Struktur 2

\begin{tabular}{|c|c|c|c|c|c|}
\hline \multirow{2}{*}{ Model } & \multicolumn{2}{|c|}{ Unstandardized Coefficients } & Standardized Coefficients & \multirow{2}{*}{$\mathrm{t}$} & \multirow[t]{2}{*}{ Sig. } \\
\hline & B & Std. Error & Beta & & \\
\hline $\begin{array}{l}\text { (Constant) } \\
\text { self efficacy }\end{array}$ & $\begin{array}{c}-6,908 \\
, 879\end{array}$ & $\begin{array}{c}4,489 \\
, 088\end{array}$ & ,403 & $\begin{array}{c}-1,539 \\
9,961\end{array}$ & $\begin{array}{l}, 125 \\
, 000\end{array}$ \\
\hline
\end{tabular}

Dependent variabel: Prestasi belajar

Sumber: SPSS ver 20

\section{Uji t variabel $X_{1}$ (Self Efficacy)}

Tabel 1 dilihat untuk koefisien $\mathrm{X}_{1}$ (Self Efficacy) diperoleh nilai t hitung dan $\mathrm{t}$ tabel dengan derajat kepercayaan 95\% satu arah diperoleh sebesar 1,649. Karena t hitung $>$ t tabel yaitu 9,961 $>1,649$, maka Ho ditolak dan Ha diterima. Yang berarti kompetensi guru berpengaruh terhadap prestasi belajar siswa SMA Negeri di kota Bandung, hal ini juga dapat diketahui dengan melihat nilai probabilitasnya yaitu sebesar 0,000 lebih kecil dari 0,05 . Besarnya pengaruh self efficacy terhadap prestasi belajar adalah $(0,403)^{2}=0,1624=16,24 \%$.

\section{Pengaruh Self Efficacy $\left(\mathrm{X}_{1}\right)$ Terhadap Prestasi Belajar (Y)}

Berdasarkan hasil analisis data penelitian dan uji signifikasi diketahui bahwa self efficacy berpengaruh positif dan signifikan terhadap prestasi belajar siswa kelas XI IPS di SMA Negeri di Kota Bandung. Hasil uji korelasi pada penelitian ini terdapat korelasi antara self efficacy dengan prestasi siswa yang diperoleh 16,24\%. Angkat tersebut memiliki arti bahwa pengaruh self efficacy terhadap prestasi belajar siswa kelas XI IPS di SMA Negeri Kota Bandung memiliki pengaruh dan sisanya dipenagruhi faktor lain. Pengaruh ini juga diperkuat dengan hasil uji signifikasi yang diperoleh sebesar 0,000 yang nilainya lebih kecil dari $\alpha=0,05(0,000<0,005)$, artinya self efficacy dan hasil belajar memiliki hubungan yang signifikan. Hal ini juga berarti semakin tinggi self efficacy maka akan semakin tinggi juga prestasi belajar siswa. Berdasarkan hasil penelitian menunjukan self efficacy berpengaruh positif terhadap prestasi 
belajar siswa pada mata pelajaran ekonomi. Artinya jika semakin tinggi self efficacy maka prestasi belajar akan semakin baik. Sebaliknya jika self efficacy rendah maka prestasi belajar siswa ikut berpengaruh rendah.

Self efficacy juga merupakan salah satu faktor yang mempengaruhi prestasi belajar, self efficacy adalah keyakinan diri yang diperoleh dari reseprestasi mental dan kognitif individu atas realitas, yang terbentuk oleh pengalaman-pengalaman masa lalu dan masa kini, dan disimpan dalam memori. Seseorang yang memiliki self efficacy tinggi meyakini bahwa dirinya mampu untuk melakukan aktivitas yang akan dilakukan. Sebaliknya, seseorang yang memiliki self efficacy yang rendah tidak yakin akan kemampuan dalam melaksanakan suatu aktivitas dan ini akan sangat berpengaruh terhadap prestasi belajar.

Hal ini sejalan dengan penelitian Anggi Ajeng Widyaninggar terdapat pengaruh antara self efficacy terhadap prestasi belajar, dimana untuk meningkatkan dan mengotimalkan prestasi belajar peserta didik salah satunya adalah dengan meningkatkan self efficacy peserta didik (Widyaninggar, 2014:9). Untuk meningkatkan self efficacy peserta didik perlu didukung oleh peningkatan hubungan antara guru, teman sejawat, keluarga dan lingkungan. Sesuai dengan pendapat Alwisol "prestasi yang pernah dicapai pada masa lalu adalah pengalam performasi. Sebagai sumber, performasi masa lalu menjadi pengubah self efficacy yang paling kuat pengaruhnya. Prestasi yang bagus meningkatkan ekspekatasi self efficacy sedangkan kegagalan akan menurunkan self efficacy (Alwisol, 2009:288). Berbagai hal yang dapat dengan mudah diamati dari seorang anak yang memiliki self efficacy diri tinggi adalah dengan: 1) memiliki kepercayaan diri lebih tinggi dibandingkan teman-temanya, 2) mempelajari materi yang belum dipelajari tanpa diperintah oleh guru, 3) memiliki keingintahuan yang tinggi, 4) tidak malu untuk bertanya, dan 5) memiliki banyak cara untuk menyelesaikan suatu masalah dalam pembelajaran (Widyaninggar, 2014:10).

Penelitian Fatiya Rosdiya, Sugeng Utaya, dan Budijanto terdapat dalam penelitian self efficacy secara signifikan berpengaruh positif terhadap prestasi belajar siswa (Rosyida, Utaya, \& Budijanto, 2016:9). Mereka yang memiliki self effcacy rendah maka nilai juga rendah dan sebaliknya. Self efficacy atau keyakinan diri memberikan pengaruh positif terhadap prestasi akademik 
seseorang. "Self efficacy was positively related to student cognitive engagement and performance" (Pitririnch dan De Groot, 1990 dalam Rosyida et al., 2016:9).

\section{SIMPULAN}

Self efficacy di SMA Negeri Kota Bandung termasuk dalam kategori sangat tinggi. Self efficacy berpengaruh positif dan signifikan terhadap prestasi belajar siswa kelas XI IPS di SMA Negeri Kota Bandung. Artinya semakin tinggi self efficacy, maka prestasi belajar akan meningkat. Pendidikan menjadi pendukung untuk setiap aktivitas manusia, dimana prestasi belajar siswa menjadi prioritas pendidikan. Salah satu tujuan pendidikan secara efektif meningkatkan prestasi belajar siswa.

Peningkatan prestasi belajar siswa menjadi permbahasan dari kalangan pendidikan, orang tua, dan masyrakat. Prestasi belajar merupakan hasil yang sangat penting karena tingginya prestasi belajar menunjukan keberhasilan suatu pendidikan yang berkualitas yaitu dengancara melakukan kajian dan penelitian terkait prestasi belajar dan faktor-faktor yang mempengaruhinya. Diharapkan pihak sekolah, guru, orang tua, masyarakat dan pemerintah mempunyai peran dalam meingkatkan prestasi belajar siswa yang akan berdampak pada meningkatnya kualitas pendidikan.

Hasil penelitian ini memberikan kontribusi dalam Mata Pelajaran Ekonomi. Dimana setiap siswa harus memiliki self efficacy yang terdiri dari Magnitude: Tingkat kesulitan tugas, Strenght: Keyakinan siswa dalam mengatasi kesulitan belajar, dan Generality: Keyakinan siswa terhadap kemampuan menyelesaikan tugas pada Mata Pelajaran Ekonomi sehingga akan meningkatkan prestasi belajar siswa.

\section{SARAN}

Dalam upaya meningkatkan prestasi disarankan guru untuk meningkatkan self efficacy, self efficacy adalah keyakinan seseorang mampu menjalankan perilaku tertentu untuk mencapai tujuan tertentu. Seseorang yang memiliki self efficacy tinggi meyakini bahwa dirinya mampu untuk melakukan aktivitas yang akan dilakukan. Bagi peneliti selanjutnya, sebaiknya peneliti dilakukan dengan menambah lagi variabel-variabel yang belum diteliti dalam penelitian ini, agar 
penelitian selanjutny lebih luas sehingga dapat memcahkan masalah prestasi belajar, khususnya pada mata pelajaran ekonomi.

\section{REFERENSI}

Afari, E., Ward, G., \& Khine, M. S. (2012). Global self-esteem and self-efficacy correlates: Relation of academic achievement and self-esteem among Emirati students. International Education Studies, 5(2), 49-57. https://doi.org/10.5539/ies.v5n2p49

Alwisol. (2009). Psikologi Kepribadian. Malang: UMM Press.

Atya, R. (2017). Pengaruh Self Efficacy terhadap Hasil Belajar Mahasiswa Berprestasi STKIP PGRI Bangkalan. Equilibrium, 5(2), 117-122.

Butters, R., Asarta, C., \& Thompson, E. (2013). The Production of Economic Knowledge in Urban and Rural Areas: The Role of Student, Teacher, and School Characteristics. Journal of Agricultural and Applied Economics, $45(1), 1-15$.

Korelich, K., \& Maxwell, G. (2015). The Board of Trustees' professional development and effects on student achievement. Research in Higher Education Journal, 27(27), 1-15.

Mahyuddin, R., Elias, H., Cheong, L. S., Muhamad, M. F., Noordin, N., \& Abdullah, M. C. (2006). THE RELATIONSHIP BETWEEN STUDENTS , SELF EFFICACY AND THEIR ENGLISH LANGUAGE ACHIEVEMENT. Pendidik Dan Pendidikan, (1996), 61-71.

Mason, M. (2000). Teachers as Critical Mediators of Knowledge. Journal of Philosophy of Education, 34(2), 343-352. https://doi.org/10.1111/14679752.00177

Mead, N., \& Sandene, B. (2007). Economics 2006 Contents What is The Nation 's Report Card? The Nation's Report Card: Economics 2006.

Minauli, T. H. dan I. (2015). Hubungan Antara Kecerdasan Emosi dan Efikasi Diri Dengan Prestasi Belajar. Psikologi, 1, 50-56.

Muhibbin, S. (2008). Psikologi Belajar. Jakarta: PT Raja Grafindo Persada.

Muhidin, S. dan. (2011). Desain Penelitian Kuantitatif, Panduan Praktis Bagi Dosen dan Mahasiswa.

NCES. (2013). The Nation's Report Card: Economics 2012. 
Rosyida, F., Utaya, S., \& Budijanto. (2016). Pengaruh Kebiasaan Belajar Dan Self Efficacy Terhadap Hasil Belajar Geografi di SMA. Jurnal Pendidikan Geografi, 2, 17-28.

Sedaghat, M., Abedin, A., \& Hejazi, E. (2011). Motivation , cognitive engagement, and academic achievement. Elsevier, 15, 2406-2410. https://doi.org/10.1016/j.sbspro.2011.04.117

Sugiyono. (2010). MetodePenelitian Kuantitatif Kualitatif \& RND.

Thompson, E., Butters, R. B., \& Asarta, C. J. (2011). The Gender Question in Economics: Is it the Teacher or is it the Test? Innovation (Vol. 9).

Uno, Hamzah B. dan Mohammad, N. (2011). Belajar dengan Pendekatan Pailkem. Jakarta: Bumi Aksara.

Widyaninggar, A. A. (2014). Pengaruh Efikasi Diri Dan Lokus Kendali (Locus of Control) Terhadap Prestasi Belajar Matematika. Jurnal Formatif, 4(2), 89-99. 